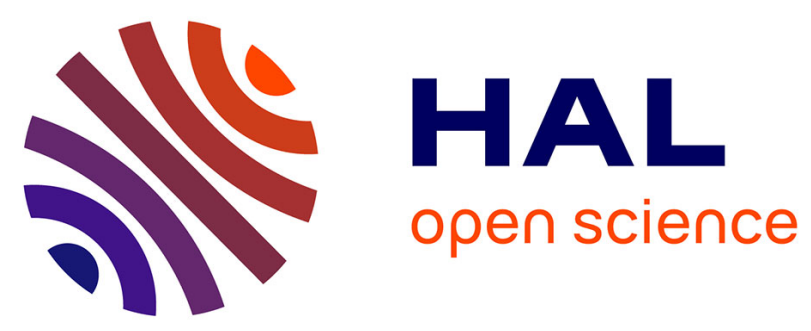

\title{
Clonal expansions in selected TCR BV families of rheumatoid arthritis patients are reduced by treatment with the TNF $\alpha$ inhibitors etanercept and infliximab
}

Matthias Pierer, Manuela Rossol, Sylke Kaltenhäuser, Sybille Arnold, Holm Häntzschel, Christoph Baerwald, Ulf Wagner

\section{To cite this version:}

Matthias Pierer, Manuela Rossol, Sylke Kaltenhäuser, Sybille Arnold, Holm Häntzschel, et al.. Clonal expansions in selected TCR BV families of rheumatoid arthritis patients are reduced by treatment with the TNF $\alpha$ inhibitors etanercept and infliximab. Rheumatology International, 2010, 31 (8), pp.1023-1029. 10.1007/s00296-010-1402-9 . hal-00615344

\author{
HAL Id: hal-00615344 \\ https://hal.science/hal-00615344
}

Submitted on 19 Aug 2011

HAL is a multi-disciplinary open access archive for the deposit and dissemination of scientific research documents, whether they are published or not. The documents may come from teaching and research institutions in France or abroad, or from public or private research centers.
L'archive ouverte pluridisciplinaire HAL, est destinée au dépôt et à la diffusion de documents scientifiques de niveau recherche, publiés ou non, émanant des établissements d'enseignement et de recherche français ou étrangers, des laboratoires publics ou privés. 
Clonal expansions in selected TCR BV families of rheumatoid arthritis patients are reduced by treatment with the TNF $\alpha$ inhibitors Etanercept and Infliximab

Matthias Pierer, MD, Manuela Rossol, MD, Sylke Kaltenhäuser, MD, Sybille Arnold, MD, Holm Häntzschel, MD, Christoph Baerwald, Ulf Wagner, MD

Department of Medicine II, University of Leipzig, Johannisallee 30, 04103 Leipzig, Germany

Key words: Rheumatoid Arthritis, T Lymphocytes, clonal expansion, TNFa, IL-7, CD28

Address correspondence to: Matthias Pierer, Department of Medicine II, University of Leipzig, Liebigstrasse 22,

04103 Leipzig, Germany

Tel.: +49-341-97-24801, Fax.: +49-341-97-24829

E-mail: matthias.pierer@medizin.uni-leipzig.de 


\begin{abstract}
Clonal expansions of autoreactive CD4+ $\mathrm{T}$ cells are frequently present in patients with rheumatoid arthritis (RA), and are stable over long periods of time. This study was undertaken to investigate the influence of anti- TNFa treatment on such clonal expansions in the peripheral CD4+ T cell compartment.

TNF $\alpha$ inhibiting therapies significantly reduced the total number of expanded clonotypes. This effect was mainly observed in clonal expansions in the BV6 family, while in clonal expansions of the BV14 family no such effect was seen. No change in the percentage of CD4+CD28null T cells was observed. Serum concentrations of the pro-homeostatic cytokine IL-7 were found to increase in patients responding TNF $\alpha$ inhibiting therapy.

These data argue for a normalization of adaptive immune mechanisms under TNF $\alpha$ inhibiting therapies, which may be secondary to the control of inflammation but contribute to the efficacy of cytokine blockade therapy.
\end{abstract}




\section{Introduction}

CD4+ $\mathrm{T}$ cells are implicated in the pathogenesis of rheumatoid arthritis (RA), since disease susceptibility is influenced by the presence of HLA class II alleles containing the "shared epitope" and of polymorphisms in the genes for PTPN22, STAT4 and CTLA4, all of which are relevant for $\mathrm{T}$ cell activation and function [1]. The clinical efficacy of therapeutic blockade of $\mathrm{T}$ cell costimulation by a CTLA4-Ig fusion protein (abatacept) adds further support to this pathogenic concept.

The most readily detectable pathologic finding in RA are massively expanded $\mathrm{T}$ cell clones which are present both in the peripheral circulation and in the synovial membrane of afflicted patients, and which are characterized by phenotypical abnormalities, with the loss of the ubiquitous costimulatory molecule CD28 and the gain of certain NK cell receptors being most prominent. The expanded clones have been shown to preferentially use certain BV family elements, to be associated with more severe, extra-articular disease, and to be stable in patients over long periods of time [2]. One underlying mechanism of this clonal expansion is an excessive homeostatic proliferation, which leads to proliferative exhaustion with telomere shortening in RA T cells and decreased proliferative potential, and which is driven during direct cell contact by an excess of membrane-bound TNFa [3].

The pivotal role of the cytokine TNFa in the pathogenesis is highlighted by the clinical success of TNF $\alpha$ inhibiting therapies, and an increased TNF $\alpha$ load is present in the synovitic joints and in the serum of patients with RA. The chronically increased TNF $\alpha$ levels can cause transcriptional silencing of the CD28 gene in autoreactive T cells [4], while TNF $\alpha$ inhibiting therapies have been reported to increase CD28 expression [5] and to decrease the size of the CD4+CD28null compartment of RA patients [6]. Recent reports have indicated, however, that in addition to the autoimmune disease, other factors like chronic CMV infection influence the size of the CD4+CD28null compartment. 
While loss of CD28 expression in CD4+ T cells is strongly correlated with the degree of oligoclonality, this is not equally true for all BV families. We could demonstrate previously, that only the number of BV14, but not of BV6 clones was related to the size of the CD4+CD28 null compartment. Within the BV14 family, only the occurrence of clones using the BV14-BJ1S2 and BV14-BJ2S3 combinations, but not of BV14-BJ2S7 clones correlated with the percentage of CD4+CD28null cells [7].

Therefore, while normalization of CD28 expression under TNF $\alpha$ inhibiting therapies has been investigated, no studies on the influence of TNF $\alpha$ blockade on the size and frequency of expanded clones in the peripheral blood has been published. The goal of our study was to directly analyze the influence of TNF $\alpha$ inhibition on the expanded clones, and to correlate it with the size of the CD4+CD28 null compartment. 


\section{Patients and methods}

\section{Study population}

28 Patients with RA according to the 1987 ACR criteria were enrolled into the prospective study (for details see table 1). All patients were eligible to receive anti-TNF $\alpha$ treatment according to current guidelines. Patients were either treated with intravenous infliximab infusions (Centocor, Malvern, PA) at a dose of $3 \mathrm{mg} / \mathrm{kg}$ body weight at week 0, 2, 6 and thereafter every 8 weeks or etanercept $25 \mathrm{mg}$ (Wyeth, Madison, New Jersey) twice weekly subcutaneous injections. Clinical data collected included the number of tender and swollen joints (28 joint count), the duration of morning stiffness and patients assessment of pain on the visual analogue scale. Blood was obtained before study entry and after 2, 4 and 12 months in both treatment groups). Clinical responses to therapy were independently monitored by the treating physicians, using the Disease Activity Score 28 CRP (DAS28 CRP). Patients were classified as non-, moderate, or good responders, dependent on the extent of change and the level of disease activity reached according to the EULAR response criteria. The patients analyzed in the study were treated for a minimum of one year and all patients followed achieved at least a moderate DAS28 response. The study participants provided written informed consent. All protocols have been approved by the institutional review board of the University of Leipzig.

\section{Spectratyping}

The determination of $\mathrm{T}$ cell oligoclonality was performed as published previously [7]. The analysis was performed before initiation of treatment and after 4 and 12 months. For the etanercept group, the time point 2 months after initiation of treatment was added. In brief, CD4+ T cells were isolated by Ficoll- Paque density gradient centrifugation separated PBMCs using negative selection by immunomagnetic separation (CD4+ T cell Isolation Kit, Miltenyi BioTech). The purity of isolated CD4+ T cells was routinely tested by FACS analysis using anti-CD4 antibody (Becton Dickinson) and was found not to be less than 97 percent. Total cellular RNA was extracted using Trizol method (Invitrogen) and transcribed into cDNA 
using cDNA synthesis kit (Roche). To control for equal efficiency of RNA extraction and cDNA transcription, a control PCR using primers for GAPDH was performed. TCR $\beta$ chain transcripts were amplified in a nested PCR using primers specific for BV6 and BV14 and a constant region primer in the first round of amplification followed by a second round with a $\mathrm{J} \beta$ specific primer panel (BJ1S2, BJ2S3 and BJ2S7) combined with the $\mathrm{V} \beta$ primer used in the first round of amplification (primers from BioTez). All primer sequences were used as published. The products were than radiolabeled with ${ }^{32} \mathrm{P}$ ATP (Amersham Biosciences) and run on a polyacrylamide electrophoresis gel. The resulting spectratypes were scanned on a phosphoimager and analyzed using the software package multianalyst (Biorad). Peaks representing overexpressed CDR3 lengths were judged as being clonally expanded if their height exceeded neighbouring peaks by at least $40 \%$. For 10 arbitrarily chosen clonal peaks, bands were excised and DNA was extracted. Direct sequencing of re-amplified PCR products from those extracted bands revealed monoclonal TCR $\beta$ chain sequences in all cases (Big Dye Terminator Cycle sequncing, Applied Biosystems, ABI Prims 310 automated Sequencer).

\section{Flow cytometry}

For the analysis of the CD4+CD28 null $\mathrm{T}$ cell compartment, PBMC were isolated from peripheral blood using a Ficoll-Paque density gradient centrifugation. Cells were incubated with anti-CD4 FITC and anti-CD28 PE antibodies (Becton Dickinson) for 30 minutes, washed twice with PBS and analyzed using a FACS Calibur (Beckton Dickinson).

\section{ELISA}

Sera from the indicated time points were prepared immediately after the blood drawings and stored frozen at $-80^{\circ}$. Concentrations of IL-7 were measured by Elisa according to the manufacturers instructions (Quantikine, R\&D systems, Minneapolis, MN).

\section{Statistical analysis.}


For statistical analysis, the software package Sigma Stat (SPSS Inc., Chicago, IL) was used.

Student's T-test, Wilcoxon signed rank test or Pearson product moment correlation were used if appropriate.

\section{Results}

\section{CD4positive CD28null T cells remain unaffected during anti TNF treatment}

In both treatment groups (infliximab and etanercept), a proportion of patients showed an expanded CD4+CD28 null T cell compartment at baseline. The mean percentage of CD28 null $\mathrm{T}$ cells was $5.4 \%$ in the etanercept group and $8.0 \%$ in the infliximab group, and was therefore comparable to a larger RA cohort analyzed previously [7].

In both study cohorts treated either with etanercept $(n=19)$ or infliximab $(n=9)$, patients were analyzed before treatment initiation and after 2, 4 and 12 months by flow cytometry. No significant changes in the percentage of CD4+CD28 null cells at the analyzed time points compared to base line values were detectable (figure $1 \mathrm{~A}$ and B). The number of patients with a significantly expanded CD4+CD28 null $\mathrm{T}$ cell compartment also remained stable during both therapies (data not shown). Response to therapy was not related to the size of the CD4+ CD28 null $\mathrm{T}$ cell compartment at baseline or during the course of TNF $\alpha$-inhibiting therapy (figure $1 \mathrm{C}$ ).

\section{Analysis of CD4+ T cell clonal expansions}

For the analysis of clonal expansions, the BV6 and BV14 TCR $\beta$ chain families were chosen as reported earlier, since both have been described to frequently contain multiple expanded clonotypes in RA [8, 9]. BV6.2 and BV14 primers were used in combination with primers specific for BJ1S2, BJ2S3 and BJ2S7 elements, as published previously [7].

In the 19 patients of the etanercept group, a total of 54 expanded clonotypes was detected at baseline, with 28 of the clones using BV6 and 26 of the clones using BV14 $\beta$ elements. The 
Patients had a median number of 1 clone in the BV6 and 2 clones in the BV14 family before initiation of treatment. Similarly, the 9 patients in the infliximab group had 30 clones in the BV6 and 19 in the BV14 family, resulting in a median of 2 BV6 and 2 BV 14 clones per patient.

After initiation of TNF $\alpha$ inhibiting therapy, clonal expansions were determined at several time points. In both treatment cohorts, the overall number of expanded clonotypes decreased with longer duration of therapy, and this decrease reached statistical significance after 4 months in both treatment groups (figure 2).

However, a clear difference between the two BV families analyzed was discernible. While the number of BV6 clonotypes declined significantly, no change in the number of BV14 clones was detected (figures 3 and 4). The BJ elements used by the expanded clonotypes did not influence the decline or persistence of the number of detected clones. No influence of baseline disease activity or response to therapy at the end of the study on the number of clonotypes in the analyzed BV families was detected. The percentage of CD4+CD28 null T cells during the study did not correlate with the number of detected clonotypes (data not shown).

\section{Serum IL-7 concentrations increase during treatment with TNFa inhibitors}

As an indicator for physiological homeostatic mechanisms which influence the peripheral $\mathrm{T}$ cell pool, serum levels of the pro-homeostatic cytokine IL-7 were determined in 12 etanercept treated patients and 8 infliximab treated patients, which are included in the previous analysis, before initiation and after 4 months of therapy. We found a significant increase $(\mathrm{p}<0.05)$ of serum IL7 concentration under therapy compared to baseline (figure 5 A). This increase was dependent on the clinical response, since it was found significantly more frequently in patients with a moderate or good response after 4 months according to the DAS28 response criteria $(n=15)$, but not in non-responders $(n=5$, figure 5B). However, no significant 
correlation between the number of clonal expansions and IL-7 concentrations was discerned (figure $5 \mathrm{C}$ ). 


\section{Discussion}

Expanded CD4+ T cell clones are a hallmark of the autoimmune disease rheumatoid arthritis. Their naive phenotype [10], the emergence of dominant clones following therapeutic $\mathrm{T}$ cell depletion [11] and a suspected genetic influence on their development [12] suggest that, among others, dysregulated homeostatic proliferation of naive T cells plays an important role. Accordingly, maintenance of the circulating $\mathrm{T}$ cell pool seems compromised in patients with RA, resulting in a disturbed regulation of $\mathrm{T}$ cell homeostasis [13], which is driven by aberrant mechanisms like the direct intercellular contact with membrane anchored TNFa [3].

The preferential use of certain BV and BJ elements in the expanded clonotypes indicates that TCR specificity might play a role $[7,14]$. Finally, a contribution of viral pathogens to the generation of $\mathrm{T}$ cell clones has been suggested $[15,16]$.

The reduction of expanded clonotypes under TNF $\alpha$ inhibiting therapy is a sign of reconstitution of the immune system, which is most likely beneficial for the patient. The cytokine IL-7 is known to stimulate thymic output of T cells as well as the expansion of naïve peripheral T cells. In RA patients a relative IL-7 deficiency has been reported [17]. The increase of serum IL-7 levels during anti-TNF $\alpha$ therapy shown here could therefore contribute to the observed clonal reduction. However, conflicting results have been reported for IL-7 serum levels in RA patients and also during the treatment with the TNF $\alpha$ inhibitor adalimumab [18]. Within inflamed joints of RA patients, increased levels of IL-7 have been demonstrated and a pro-inflammatory effect of IL-7 on macrophages, osteoclasts and other resident cells has been established [19]. Further studies are needed for conclusive evidence for a beneficial effect of increased serum concentration of this cytokine.

The differential decline of BV6- compared to BV14-containing clonal expansions under therapeutic TNF $\alpha$ inhibition supports previous findings by our group and others indicating profound differences between BV families, possibly due to differential antigen specificity. 
The persistence of BV14 clones might be due to an independence from inflammatory disease activity in contrast to BV6 clones, which might be induced by the pro-inflammatory cytokine milieu and TNF $\alpha$ inhibiting therapy with a good anti-inflammatory efficacy might therefore preferentially lower clonal expansions of BV6 clones. .Whether remaining, mainly BV14 family clonal expansions contribute to the flare up of disease after discontinuation of TNF $\alpha$ inhibiting therapies remains to be studied. Similarly, the failure of TNF $\alpha$ inhibiting therapies to significantly decrease $\mathrm{CD} 4+\mathrm{CD} 28$ null $\mathrm{T}$ cells in our study cohort could indicate persistence of autoreactivity in the $\mathrm{T}$ cell pool despite good clinical response, although conflicting results have also been reported $[5,6,20]$.

In conclusion, the study provides evidence for a normalizing influence of $\mathrm{TNF} \alpha$ inhibiting therapy on clonal expansions in the circulating CD4+ T cell pool, which might be mediated in part by an increase in serum IL-7 levels.

\section{References}

1 K.H. Costenbader, S.C. Chang, I. De Vivo, R. Plenge, E.W. Karlson, Genetic polymorphisms in PTPN22, PADI-4, and CTLA-4 and risk for rheumatoid arthritis in two longitudinal cohort studies: evidence of gene-environment interactions with heavy cigarette smoking, Arthritis. Res. Ther. 10 (2008):R52.

2 K. Koetz, E. Bryl, K. Spickschen, W.M. O'Fallon, J.J. Goronzy, C.M. Weyand, T cell homeostasis in patients with rheumatoid arthritis, Proc. Natl. Acad. Sci. U. S. A. 97 (2000) 9203-9208.

3 U. Wagner, M. Pierer, M. Wahle, F. Moritz, S. Kaltenhäuser, H. Häntzschel, Ex vivo homeostatic proliferation of $\mathrm{CD} 4+\mathrm{T}$ cells in rheumatoid arthritis is dysregulated and driven by membraneanchored TNFalpha, J. Immunol. 173 (2004) 2825-2833.

4 E. Bryl, A.N. Vallejo, C.M. Weyand, J.J. Goronzy, Down-regulation of CD28 expression by TNFalpha, J. Immunol. 167 (2001) 3231-3238.

5 E. Bryl, A.N. Vallejo, E.L. Matteson, J.M. Witkowski, C.M. Weyand, J.J. Goronzy, Modulation of CD28 expression with anti-tumor necrosis factor alpha therapy in rheumatoid arthritis, Arthritis. Rheum. 52 (2005) 2996-3003. 
6 A. Pawlik, L. Ostanek, I. Brzosko, M. Brzosko, M. Masiuk, B. Machalinski, B.G. Szklarz, Therapy with infliximab decreases the CD4+CD28- T cell compartment in peripheral blood in patients with rheumatoid arthritis, Rheumatol. Int. 24 (2004) 351-354.

7 U. Wagner, M. Pierer, S. Kaltenhäuser, B. Wilke, W. Seidel, S. Arnold, H. Häntzschel, Clonally expanded CD4+CD28null $T$ cells in rheumatoid arthritis use distinct combinations of $T$ cell receptor BV and BJ elements, Eur. J. Immunol. 33 (2003) 79-84.

8 D. Schmidt, P.B. Martens, C.M. Weyand, J.J. Goronzy, The repertoire of CD4+ CD28- T cells in rheumatoid arthritis, Mol. Med. 2 (1996) 608-618.

9 X. Paliard, S.G. West, J.A. Lafferty, J.R. Clements, J.W. Kappler, P. Marrack, B.L. Kotzin, Evidence for the effects of a superantigen in rheumatoid arthritis, Science. 253 (1991) 325-329.

10 D. Schmidt, J.J. Goronzy, C.M. Weyand, CD4+ CD7- CD28- T cells are expanded in rheumatoid arthritis and are characterized by autoreactivity, J. Clin. Invest. 97 (1996) 2027-2037.

11 M.C. Jendro, T. Ganten, E.L. Matteson, C.M. Weyand, J.J. Goronzy, Emergence of oligoclonal T cell populations following therapeutic T cell depletion in rheumatoid arthritis, Arthritis. Rheum. 38 (1995) 1242-1251.

12 I. Waase, C. Kayser, P.J. Carlson, J.J. Goronzy, C.M. Weyand, Oligoclonal T cell proliferation in patients with rheumatoid arthritis and their unaffected siblings, Arthritis. Rheum. 39 (1996) 904913.

13 J.J. Goronzy, C.M. Weyand, Aging, autoimmunity and arthritis: T-cell senescence and contraction of T-cell repertoire diversity - catalysts of autoimmunity and chronic inflammation, Arthritis. Res. Ther. 5 (2003) 225-234.

14 J.B. Reiser, C. Grégoire, C. Darnault, T. Mosser, A. Guimezanes, A.M. Schmitt-Verhulst, et al, A T cell receptor CDR3beta loop undergoes conformational changes of unprecedented magnitude upon binding to a peptide/MHC class I complex, Immunity. 16 (2002) 345-354.

15 R. Thomas, M. Turner, A.P. Cope, High avidity autoreactive T cells with a low signalling capacity through the T-cell receptor: central to rheumatoid arthritis pathogenesis? Arthritis. Res. Ther. 10 (2008):210.

16 M. Hooper, E.G. Kallas, D. Coffin, D. Campbell, T.G. Evans, R.J. Looney, Cytomegalovirus seropositivity is associated with the expansion of CD4+CD28- and CD8+CD28- $T$ cells in rheumatoid arthritis, J. Rheumatol. 26 (1999) 1452-1457. 
17 F. Ponchel, R.J. Verburg, S.J. Bingham, A.K. Brown, J. Moore, A. Protheroe, et al, Interleukin-7 deficiency in rheumatoid arthritis: consequences for therapy-induced lymphopenia, Arthritis. Res. Ther. 7 (2005) R80-R92.

18 J.A. van Roon, S.A. Hartgring, M. Wenting-van Wijk, K.M. Jacobs, P.P. Tak, J.W. Bijlsma, F.P. Lafeber, Persistence of interleukin 7 activity and levels on tumour necrosis factor alpha blockade in patients with rheumatoid arthritis, Ann. Rheum. Dis. 66 (2007) 664-669.

19 S.M. Churchman, F. Ponchel, Interleukin-7 in rheumatoid arthritis, Rheumatology. (Oxford). 47 (2008) 753-759.

20 V. Rizzello, G. Liuzzo, S. Brugaletta, A. Rebuzzi, L.M. Biasucci, F. Crea, Modulation of CD4(+)CD28null T lymphocytes by tumor necrosis factor-alpha blockade in patients with unstable angina, Circulation. 113 (2006) 2272-2277.

Acknowledgement: The work presented here was supported by grants from the German Ministry for Education and Science (Interdisziplinäres Zentrum für Klinische Forschung Leipzig, Teilprojekt A 15 and the Kompetenznetzwerk Rheuma, Entzündlich-rheumatische Systemerkrankungen, Teilprojekt C2.7)

Competing interests: The author(s) declare that they have no competing interests.

\section{Abbreviations used in this paper:}

TNF $\alpha \quad$ Tumor necrosis factor $\alpha$

CDR3 complementarity determining region 3

RA Rheumatoid arthritis

TCR T cell receptor

IL-7 Interleukin 7

CMV cytomegalovirus

BV variable region of the $\mathrm{T}$ cell receptor beta chain 


\section{Figure legends}

Fig.1: Percentage of CD4+ CD28null T cells in RA patients treated with Etanercept (A), Infliximab (B) or in responders and non-responders to both TNF $\alpha$-inhibiting therapies in $(\mathrm{C})$. Depicted are mean and SEM of the percentage of CD4+CD28null T cells before initiation of $\mathrm{TNF} \alpha$ inhibition and after the indicated duration of treatment with etanercept $(\mathrm{n}=19)$ and infliximab ( $\mathrm{n}=9)$ in $(\mathrm{A})$ and $(\mathrm{B})$. In $(\mathrm{C}), \mathrm{CD} 4+\mathrm{CD} 28$ null $\mathrm{T}$ cell percentages over time are given for the two patient groups either classified as moderate or good responders to therapy or as patients with a poor response (non-responder). Response to therapy was evaluated by the DAS response criteria after 4 months of therapy. The dashed line depicts non-responders and the solid line responders to therapy. No statistically significant differences between time points (A and B) and responders or non-responders (C) are discernable (t- test).

Fig.2: Total number of clonal expansions in the BV6 and BV14 family of T cell receptor specificities under therapy.

Each data point indicates the total numbers of clonal expansions detected in one individual patient at baseline and at the given time points following initiation of therapy with Etanercept $(A, n=19)$ or Infliximab (B, n=9). Lines depict medians; levels of significance are given for the comparison with base line values (Mann- Whitney U-test).

Fig.3: Number of clonal expansions using either BV6 or BV14 elements in the T cell receptor in patients treated with Etanercept.

Each data point represents the number of clones in the BV6 (A) or the BV14 (B) family of T cell receptors detected in one individual patient at baseline and at the given time points following initiation of therapy with Etanercept $(n=19)$. Lines depict medians; levels of significance are given for the comparison with base line values (Mann- Whitney U-test). 
Fig.4: Number of clonal expansions using BV6 or BV14 elements in patients treated with Infliximab.

Each data point represents the number of clones in the BV6 (A) or the BV14 (B) family of T cell receptors detected in individual patients treated with Infliximab $(n=9)$ at the given time points. Lines depict medians; levels of significance are given for the comparison with base line values (Mann- Whitney U-test).

Fig.5: Serum concentrations of IL-7 under TNF $\alpha$ inhibiting therapy.

(A) Depicted are median and interquartile range of IL-7 concentrations before initiation of treatment with $\mathrm{TNF} \alpha$ inhibitors and after 4 months of therapy. Level of significance is given for the comparison between the two time points (A, t-test). (B) Changes of IL-7 concentrations in patients with a moderate or good response ( $\mathrm{n}=15$, left panel) according to DAS28 response criteria or with a poor response $(n=5$, right panel). Lines indicate IL-7 concentrations at baseline and after 4 months of therapy. The increase in IL-7 concentrations between baseline and 4 months of therapy was significantly greater in responders compared to non-responders $(\mathrm{p}<0,05, \mathrm{t}$-test). (C) Total numbers of expanded clonotypes do not correlate significantly with serum concentrations of IL-7. Filled circles depict data points before treatment initiation, while open circles depict data points after 4 months of therapy $(\mathrm{p}>0.6$, Spearman rank order correlation test). 
TABLE I: Clinical characterization of the two study populations at baseline

\begin{tabular}{lcr} 
& Etanercept & Infliximab \\
& patients & patients \\
\hline Number of patients (female/male) & $19(14 / 5)$ & $9(7 / 2)$ \\
Age at disease onset [years] mean (range) & $39(19-58)$ & $41.9(19-64)$ \\
Erosive disease [number] (percent) & $15(79)$ & $8(89)$ \\
Concomitant Methotrexate [number] (percent) & $18(95)$ & $27(14-116)$ \\
Baseline CRP [mg/l] mean (range) & $35(8-99)$ & $7(78)$ \\
Patients positive for RF IgM & $14(73)$ & $245.2(0-3430)$ \\
RF IgM concentration [IU/ml] mean (range) & $262(0-1210)$ & $3(48.6)$ \\
Patients positive for anti- CCP-Ab & $15(78)$ & $71.8(0-600)$ \\
CCP-Ab concentration [IU/ml] mean (range) & $275(0-1600)$ &
\end{tabular}


Figure 1

A

B
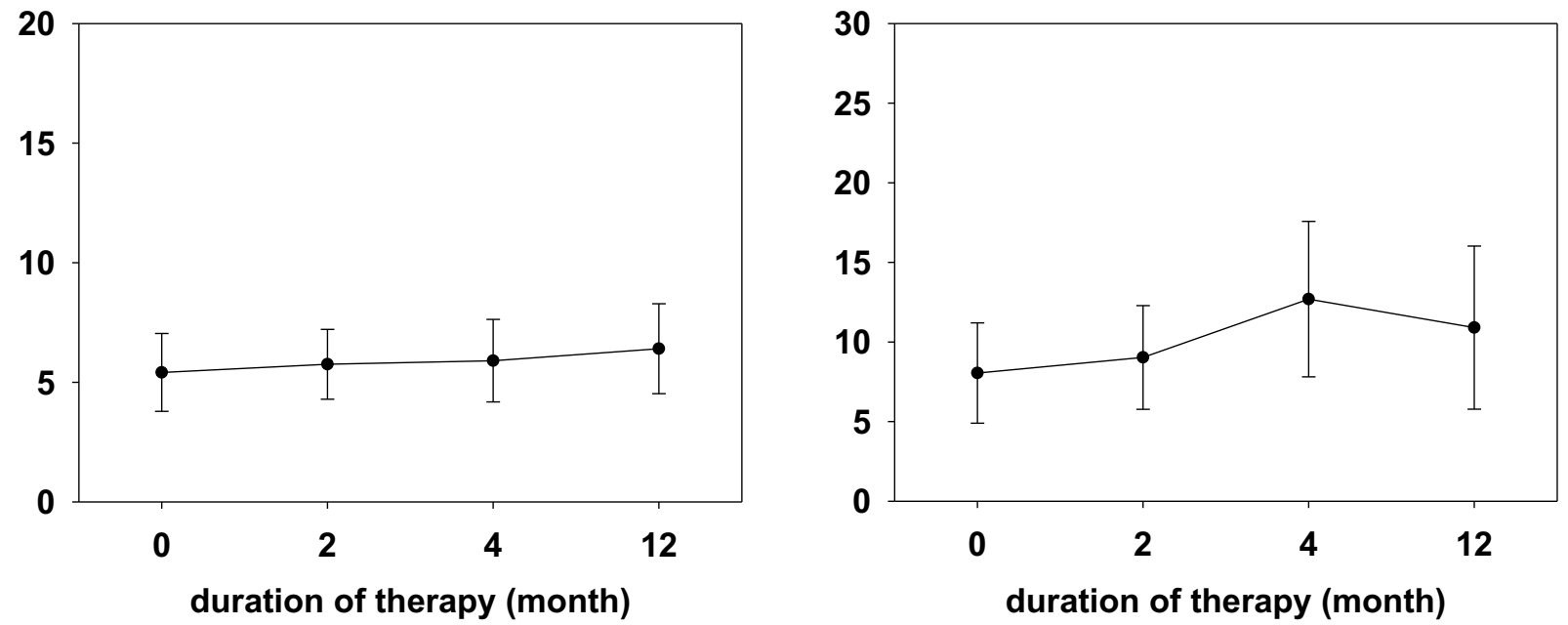

C

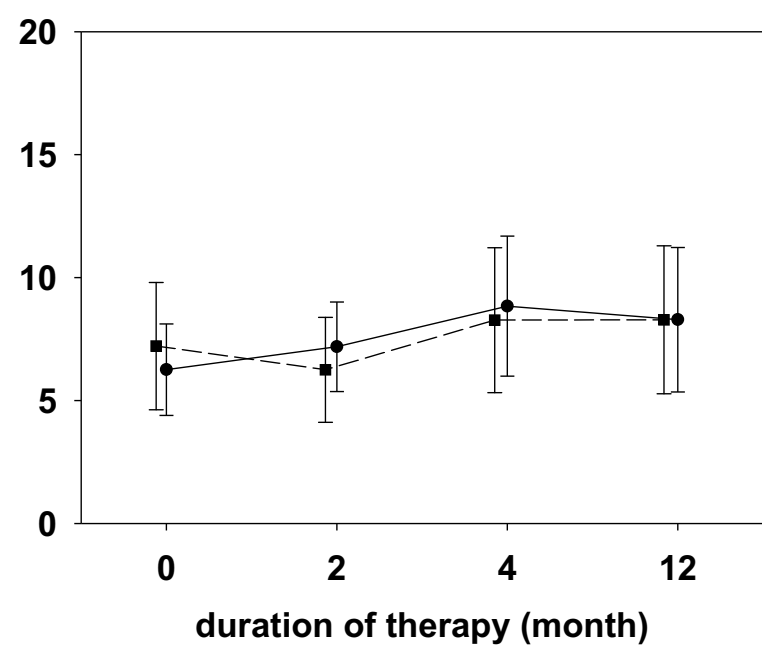

Fig.1: 
Figure 2

A

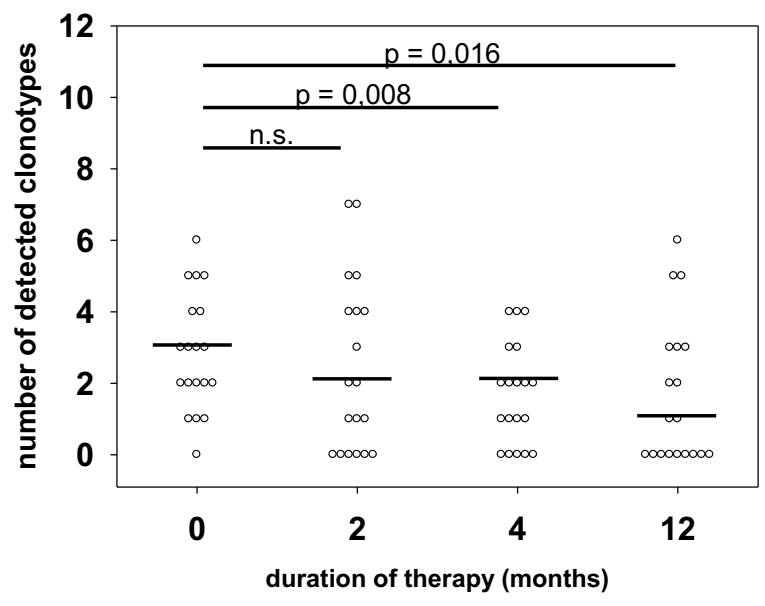

B

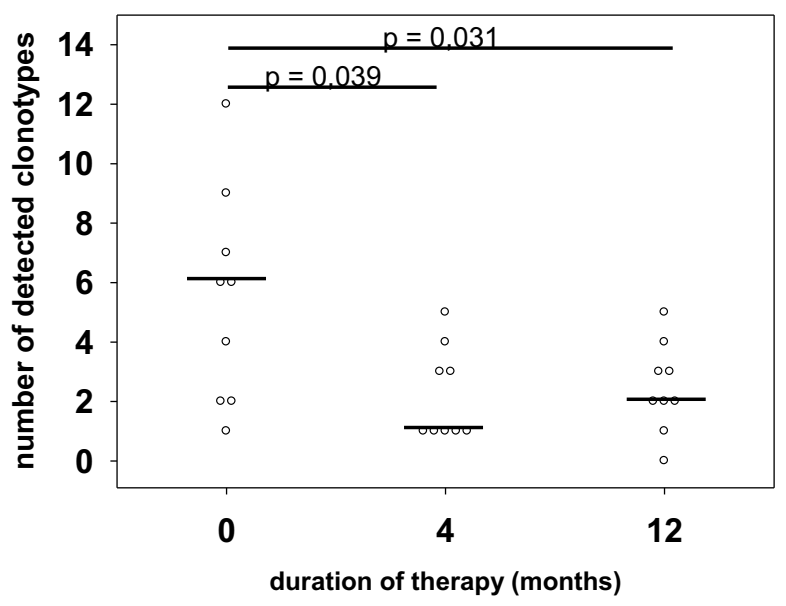

Fig.2: 
Figure 3

A

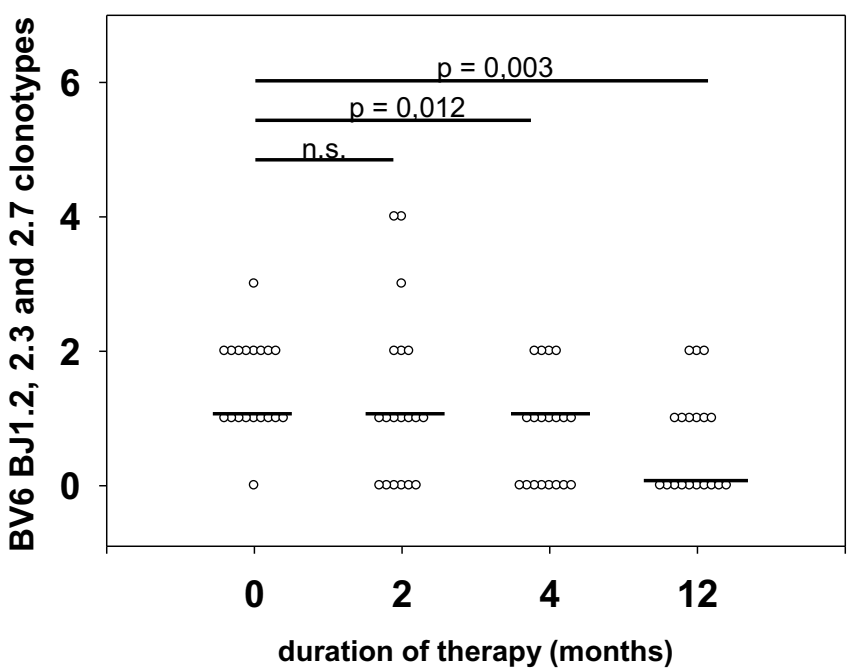

B

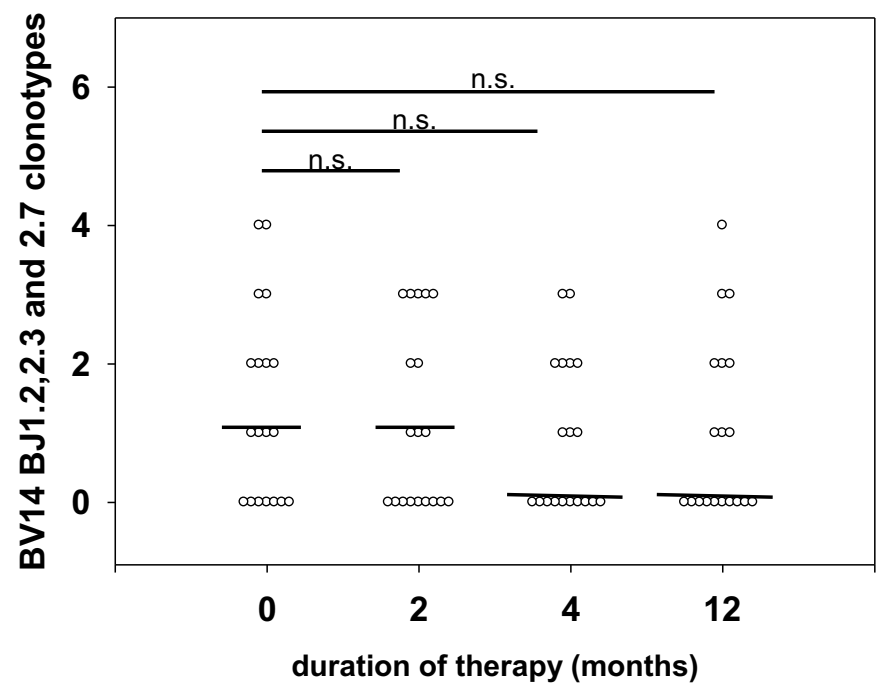

Fig.3: 
Figure 4

A

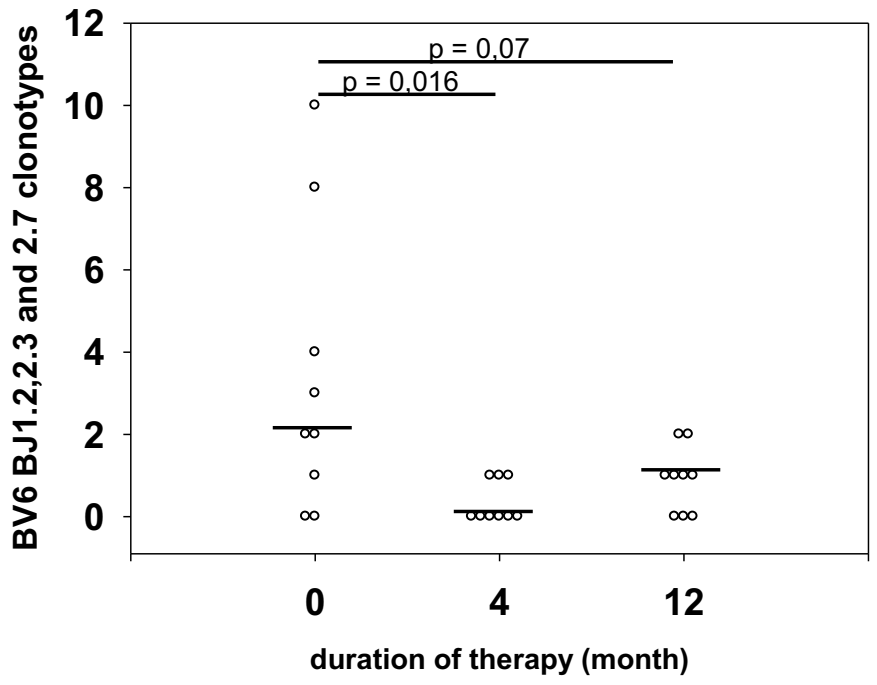

B

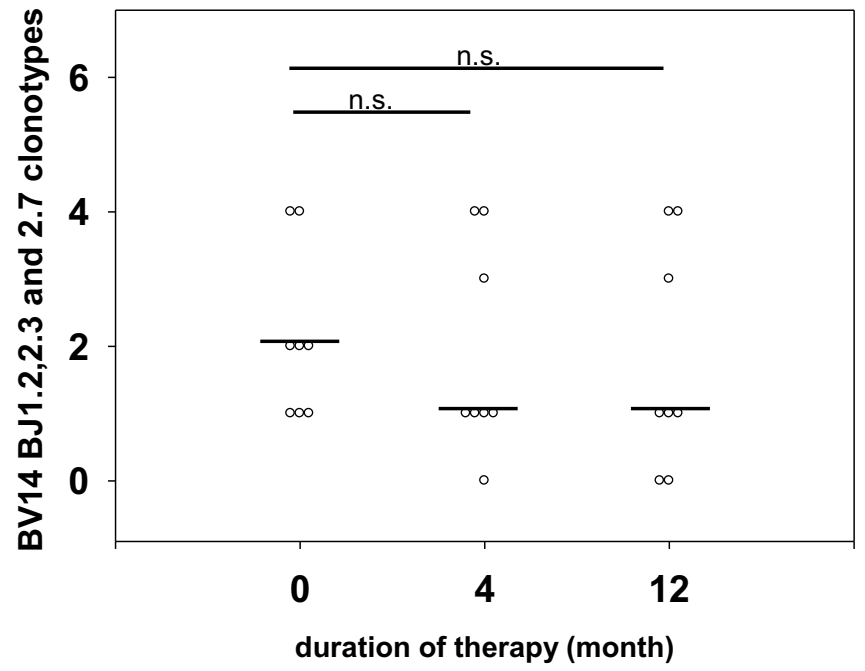

Fig.4: 
Figure 5

A

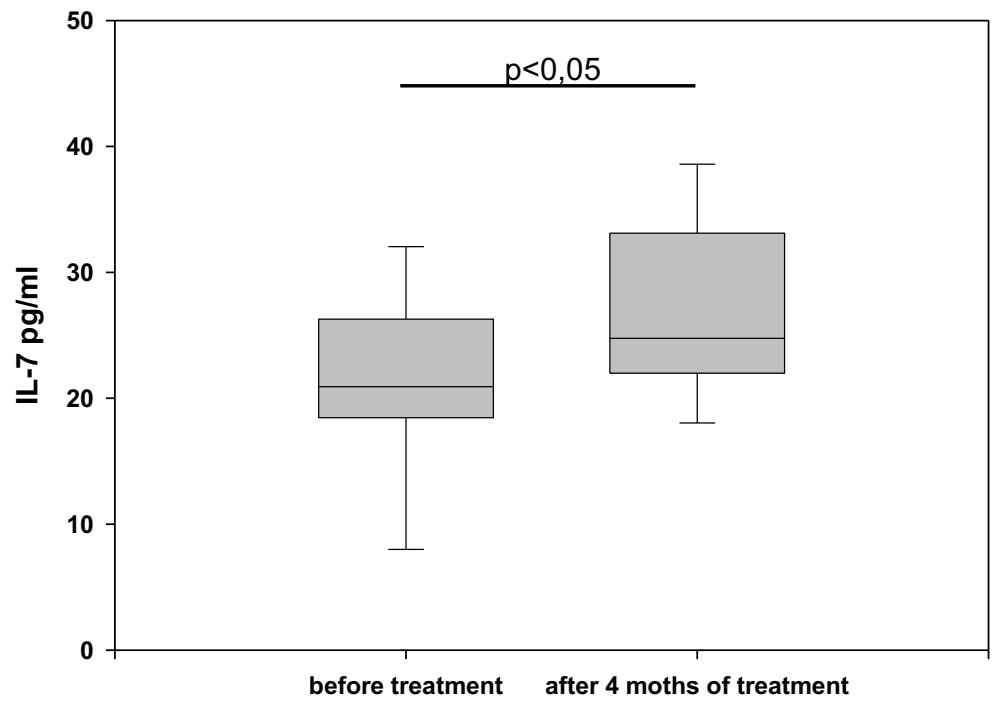

B

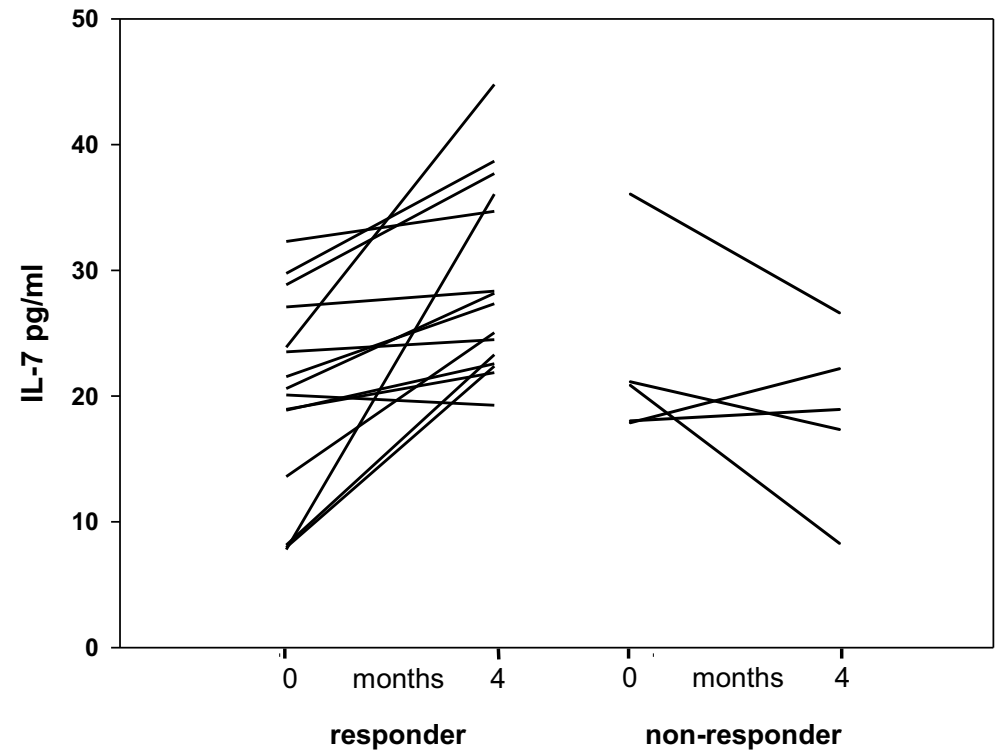

C

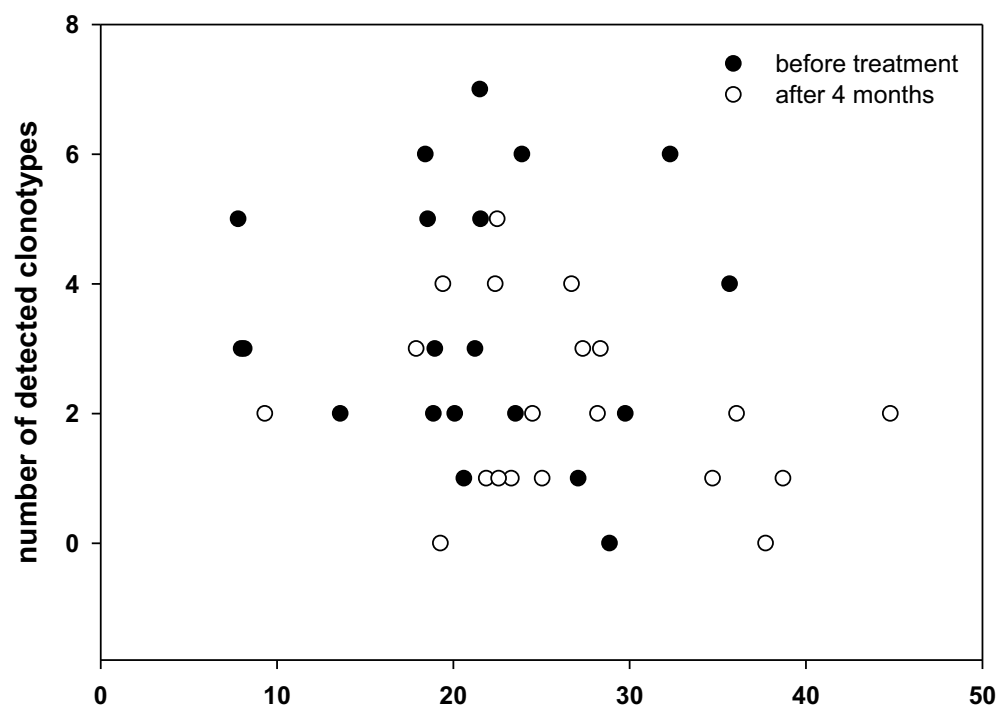

Fig.5:

IL-7 pg/ml 